\title{
Quality indicators of clinical cancer care for prostate cancer: a population-based study in southern Switzerland
}

\author{
Laura Ortelli $i^{*}$ (D), Alessandra Spitale ${ }^{1}$, Luca Mazzucchelli ${ }^{2}$ and Andrea Bordoni ${ }^{1}$
}

\begin{abstract}
Background: Quality of cancer care (QoCC) has become an important item for providers, regulators and purchasers of care worldwide. Aim of this study is to present the results of some evidence-based quality indicators (QI) for prostate cancer $(\mathrm{PC})$ at the population-based level and to compare the outcomes with data available in the literature.

Methods: The study included all PC diagnosed on a three years period analysis $(01.01 .2011-31.12 .2013)$ in the population of Canton Ticino (Southern Switzerland) extracted from the Ticino Cancer Registry database. 13 Ql, approved through the validated Delphi methodology, were calculated using the "available case" approach: 2 for diagnosis, 4 for pathology, 6 for treatment and 1 for outcome. The selection of the computed QI was based on the availability of medical documentation. Ql are presented as proportion (\%) with the corresponding 95\% confidence interval.

Results: 700 PC were detected during the three-year period 2011-2013: 78.3\% of them were diagnosed through a prostatic biopsy and for $72.5 \% 8$ or more biopsy cores were taken. $46.5 \%$ of the low risk PC patients underwent active surveillance, while $69.2 \%$ of high risk PC underwent a radical treatment (radical prostatectomy, radiotherapy or brachytherapy) and $73.5 \%$ of patients with metastatic PC were treated with hormonal therapy. The overall 30-day postoperative mortality was $0.5 \%$.

Conclusions: Results emerging from this study on the QoCC for PC in Canton Ticino are encouraging: the choice of treatment modalities seems to respect the international guidelines and our results are comparable to the scarce number of available international studies. Additional national and international standardisation of the QI and further QI population-based studies are needed in order to get a real picture of the PC diagnostic-therapeutic process progress through the definition of thresholds of minimal standard of care.
\end{abstract}

Keywords: Quality of cancer care, Prostate cancer, Quality indicators, Cancer registry, Population-based study

\section{Background}

Prostate cancer (PC) is the most frequent cancer in men. In 2012, it represented almost $22 \%$ of all new cancer diagnoses in Europe and, despite the good prognosis, it is the second leading cause of death due to cancer [1]. In Switzerland, about 6200 PC cases are diagnosed annually, representing $30 \%$ of all tumours diagnoses. With a European age-standardized incidence rate of 158.6 cases per $100^{\prime} 000$ inhabitants, the Switzerland is one of the countries with the highest incidence in Europe $[1,2]$. The

\footnotetext{
* Correspondence: laura.ortelli@ti.ch

${ }^{1}$ Ticino Cancer Registry, Cantonal Institute of Pathology, Via in Selva 24, 6600 Locarno, Switzerland

Full list of author information is available at the end of the article
}

deaths pro year are about 1300, which corresponds to a European age-standardized mortality rate equal to 21.8 cases per 100'000 inhabitants $[1,2]$. The 5 -year survival rate is $88 \%$ and is comparable to other European countries [1].

Since the late ' $90 \mathrm{~s}$, in addition to survival analysis, studies about the Quality of Cancer Care (QoCC) became increasingly important to providers, regulators and purchasers of care worldwide as they strive to systematically measure and improve care [3]. QoCC studies performed using data of cancer registries evaluate and compare the quality of care at the population-based level giving a real description of the pattern of care at the regional level, without selection bias. Moreover, research

(c) The Author(s). 2018 Open Access This article is distributed under the terms of the Creative Commons Attribution 4.0 International License (http://creativecommons.org/licenses/by/4.0/), which permits unrestricted use, distribution, and reproduction in any medium, provided you give appropriate credit to the original author(s) and the source, provide a link to the Creative Commons license, and indicate if changes were made. The Creative Commons Public Domain Dedication waiver (http://creativecommons.org/publicdomain/zero/1.0/) applies to the data made available in this article, unless otherwise stated. 
on QoCC suggests that the progresses in the diagnostic and therapeutic methodology do not always reflect directly in the clinical practice and cases of underuse and overuse of care for cancer patients may occur $[4,5]$. The data necessary for this kind of studies are available at the population-based Cancer Registries, so that, through specific quality indicators (QI), it is possible to document the delivered quality of care and provide regular feedback to healthcare workers and decision makers [6]. Moreover Cancer Registries give an independent description of the quality of care, without conflict of interest. All the structures involved in the oncological health care system in Ticino are strictly connected with the Ticino Cancer Registry allowing a complete coverage of the region.

The aim of the present study was to evaluate the results regarding 13 QI of the diagnostic and therapeutic process for PC diagnosed during the period 01.01.2011-31.12.2013 in Canton Ticino (Southern Switzerland) in order to assess the quality of PC care at the population-based level in comparison with the available literature. The 13 QI were produced by means of the Delphi process of a pool of QI derived through different guidelines. The oncological health care system in Canton Ticino includes five public hospitals, three private clinics with oncology and radiotherapy units and private oncological practices where PC patients usually undergo surgery and/or chemotherapy and/or radiotherapy. All the mentioned structures are connected with the Ticino Cancer Registry, allowing a direct access to the medical documentation necessary for the evaluation of QI and a complete coverage of the region in terms of data collection.

\section{Methods}

\section{Data sources and case selection}

All the resident population of Canton Ticino (346'539 inhabitants at 31.12.2013), the southern region of Switzerland, was included in the present study. Patients with a diagnosis of PC during the 3-year period 01.01.2011-31.12.2013 were considered eligible for the analysis. The cancer registry has a direct access to the inhabitants control office of canton Ticino, thus enabling the specific registration of patients resident in the region. For patients diagnosed or treated elsewhere we receive the corresponding documentation from other Swiss Cancer Registries. Cases were collected from the population-based Ticino Cancer Registry, which was founded in 1995 on the basis of a cantonal law and started the data collection in 1996. The Registry is part of the regional Institute of Pathology allowing the direct notification of the majority of new tumour cases; in addition, other cases are actively retrieved from public and private hospitals, radiology department, oncology centres, oncologists, general practitioners (urologists for the present study) and other Swiss Cancer Registries [7]. The information are prospectively retrieved, controlled and inserted in the Registry's database by the Registry Staff on the basis of the guidelines of the International Agency for Research on Cancer (IARC) and the recommendations of the European Network of Cancer Registry (ENCR) $[8,9]$. The Classification of Disease for Oncology (ICD-O-3) and the WHO Pathology and Genetics of Tumours of the Urinary System and Male Genital Organs are used to classify the site and the histological type of the tumour, whereas the stage is registered according to the 7th edition of the American Joint Committee on cancer (AJCC) Staging Manual [10, 11]. In order to check the validity and consistency of data, quality controls are periodically performed through several internal tests, the IARC check program (IARCcrgTools) and the Joint Research Centre - ENCR quality check software [12-14]. Standard indicators and the method of Bullard et al. are used to assess the case completeness $[7,15,16]$. Each QI was the result of an accurate data collection, performed by specific-trained data-managers, who extracted the necessary information directly from the medical documentation, thus avoiding misleading interpretations and permitting a uniform codification, necessary to achieve a good comparability level.

The D'Amico risk classification was used to define and stratify localized PC (N0, M0) for the analysis of treatment modalities (i.e. QI7-9), as following:

- low risk PC: PSA $\leq 10 \mathrm{ng} / \mathrm{ml}$ and Gleason score $\leq 6$ and clinical stage cT1-cT2a;

- intermediate risk PC: $10 \mathrm{ng} / \mathrm{ml}<\mathrm{PSA}<20 \mathrm{ng} / \mathrm{ml}$ or Gleason score $=7$ or clinical stage cT2b-cT2c;

- high risk PC: PSA $\geq 20 \mathrm{ng} / \mathrm{ml}$ or Gleason score $\geq 8$ or clinical stage cT3-cT4.

\section{List of quality indicators and analysis}

This study is part of a larger prospective, descriptive, population-based study on the QoCC in Canton Ticino, southern Switzerland, named $\mathrm{QC}_{3}$ project, with the aim to identify and compute QI for the following tumour localizations: colon-rectum, prostate, lung and ovary/ endometrium. The methodology used to select QI is in depth described in Bianchi et al. [17]. Here, a brief summary of the entire procedure. For each tumour site, we initially selected a preliminary list of evidence-based QI, through a comprehensive literature research, taking into account their degree of relevance and feasibility. A multidisciplinary team enclosing local specialists of the main medical disciplines (radio-oncology, urology for $\mathrm{PC}$, oncology and pathology) selected and approved QI through the validated Delphi methodology. QI were then submitted to an independent external international multidisciplinary Advisory Board. QI achieving an agreement greater than $70 \%$ were finally approved. Only those QI whose collection was evaluated to be "feasible at the 
population-based level" were retained. The definitive list for PC contains 23 QI, distributed in the following clinical domains: 6 for diagnosis and staging, 4 for pathology, 9 for treatment and 4 for outcome and follow-up (Additional file 1). For the present study, we computed a core of 13 QI for which all the medical documentation needed for data collection was already available at the Ticino Cancer Registry or a minor data collection was still needed to complete the analysis: 2 for diagnosis, 4 for pathology, 6 for treatment modalities and 1 for outcome (Table 1).

Each QI was defined through a numerator, i.e. the number of patients who fulfilled the specific criteria, and a denominator, i.e. the number of eligible patients. The proportion (\%) and the relative 95\% confidence interval ( $95 \%$ CI) were calculated based on the binomial distribution. Cases identified only by a death certificate (i.e. DCO cases, $0.99 \%$ ) were excluded from the present analysis. The "available case analysis" approach was used, i.e. cases for which we could not retrieve the information in the consulted medical documentation were excluded from the numerator as well from the denominator of the QI and classified as "missing".

For QIs concerning prostatic biopsies (i.e. QI1, QI2 and QI3), the transurethral prostatic resections (TUR-P) were not included in the analysis. Moreover, for QIs concerning patients operated on (QI5, QI6, QI8, QI10 and QI13), only surgical interventions performed within 6 months from the diagnosis were considered for the calculation.

For comparative goals, publications on QI were identified and selected by means of a literature search in PubMed/ MEDLINE, using initially general or specific keywords/expressions and a combination of them, such as the followings: "population-based study", "quality indicators", "quality of care or quality of cancer care", "prostate cancer", "low risk or high risk or intermediate risk", "diagnosis", "biopsy", "pathology report", "TUR-P", "prostatectomy", "treatment", "active surveillance", "radiotherapy", "dose escalation radiotherapy", "radical", "neo-adjuvant or neoadjuvant or preoperative treatment", "hormone therapy", "metastatic", "surgical margins", "outcomes", "survival", "postoperative mortality", "30-day mortality". All the peer-reviewed articles were included, except case reports, letters, abstracts or editorials.

SAS system version V9.3 (SAS Institute Inc., Cary, North Carolina, USA) was used for the analysis.

\section{Results}

Between 01.01.2011 and 31.12.2013, the Ticino Cancer Registry registered 700 diagnoses of PC. The median age at the diagnosis was 70.5 years (range: 36-100). The results for the 13 selected QI are reported in Table 1 with the following information: QI definition, numerator and denominator description (selection criteria and corresponding numbers), QI results, i.e. percentage (\%) with the corresponding $95 \% \mathrm{CI}$, list of the medical documentation analysed to retrieve the necessary information and the QI rationale.

The number of "missing", i.e. cases for whom we were not able to retrieve the needed information, was low (under $10 \%$ ) for almost all QI, with the exceptions of QI7 and QI8, for which we could not retrieve the performed treatment modality in the available medical reports for $15.5 \%(N=13)$ and $16.1 \%(N=40)$ of patients, respectively.

\section{Quality indicators for diagnosis}

QI1-2 refer to the clinical domain of the diagnosis. Overall, 535 PC were confirmed through a needle biopsy (78.3\%; 95\%CI: 75.2\%; 81.4\%) (QI1) and in 377 cases (72.5\%; 95\%CI: 68.7\%; 76.3\%) 8 or more biopsy cores were taken (QI2).

\section{Quality indicators for pathology}

QI3-6 refer to the pathology clinical domain. In our study, the biopsy pathological reports described the histology of the tumour according to the WHO definition in 498 PC (94.3\%; CI95\%: 92.4\%; 96.3\%), the differentiation grade according to Gleason score in 533 PC (99.8\%; CI95\%: 99.5\%; 100.0\%) and the proportion of sample's tissue involved by the tumour or the number of positive cores on the total number of taken specimens in 524 PC (98.9\%; CI95\%: 98.0\%; 99.8\%) (QI3). As expected by the guidelines of the College of American Pathologists and the European Society of Uropathology, we found out the following information in the pathological reports of the transurethral prostatic resection (TUR-P) (QI4): the histology description according to the WHO classification was reported in $91.4 \%$ of cases (C195\%: 85.2\%; 97.5\%), the histologic grade according to the Gleason score in $94.1 \%$ (CI95\%: 89.0\%; 99.1\%) and the proportion of tissue involved by the tumour in $72.8 \%$ (CI95\%: 63.1\%; 82.5\%) [18, 19]. The number of resected lymph nodes was reported in all patients undergoing prostatectomy with pelvic lymphadenectomy (QI5). Among the 220 patients undergoing prostatectomy with or without pelvic lymphadenectomy, the pathology report (QI6) included the information on the histological type according to WHO for 198 cases $(92.1 \%$; CI95\%: 88.5\%; 95.7\%), the histological grade according to the Gleason score for all cases, the extraprostatic extension for 198 (92.1\%; CI95\%: 88.5\%; 95.7\%), the presence of seminal vescicles invasion for 210 (97.7\%; CI95\%: 95.7\%; 99.7\%), the margins status for 216 (98.2\%; CI95\%: 96.4\%; $100.0 \%)$ and the pathological stage of the disease according to the AJCC TNM 7th edition for 219 (99.6\%; CI95\%: 98.7\%; 100.0\%) [11]. 


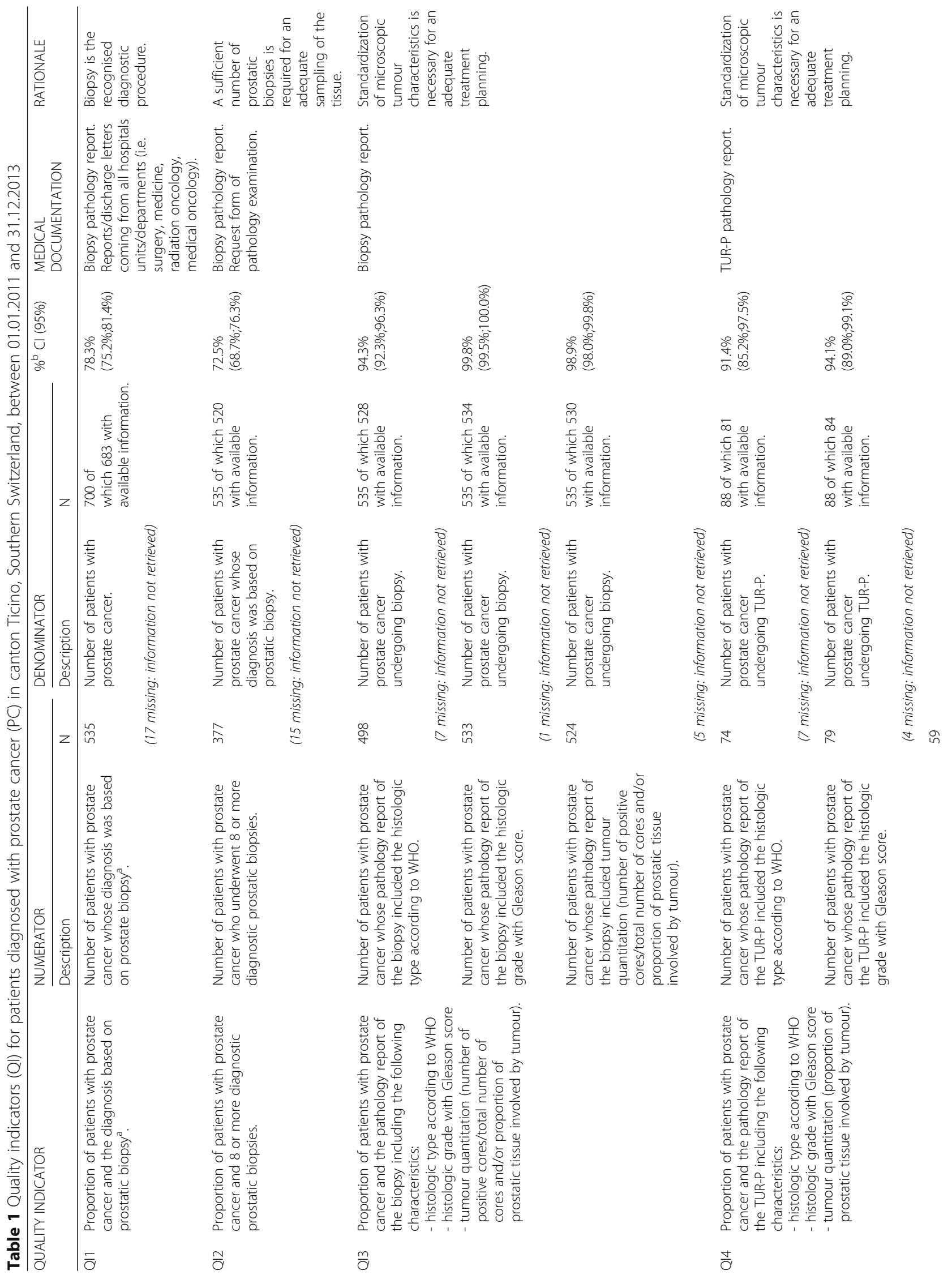




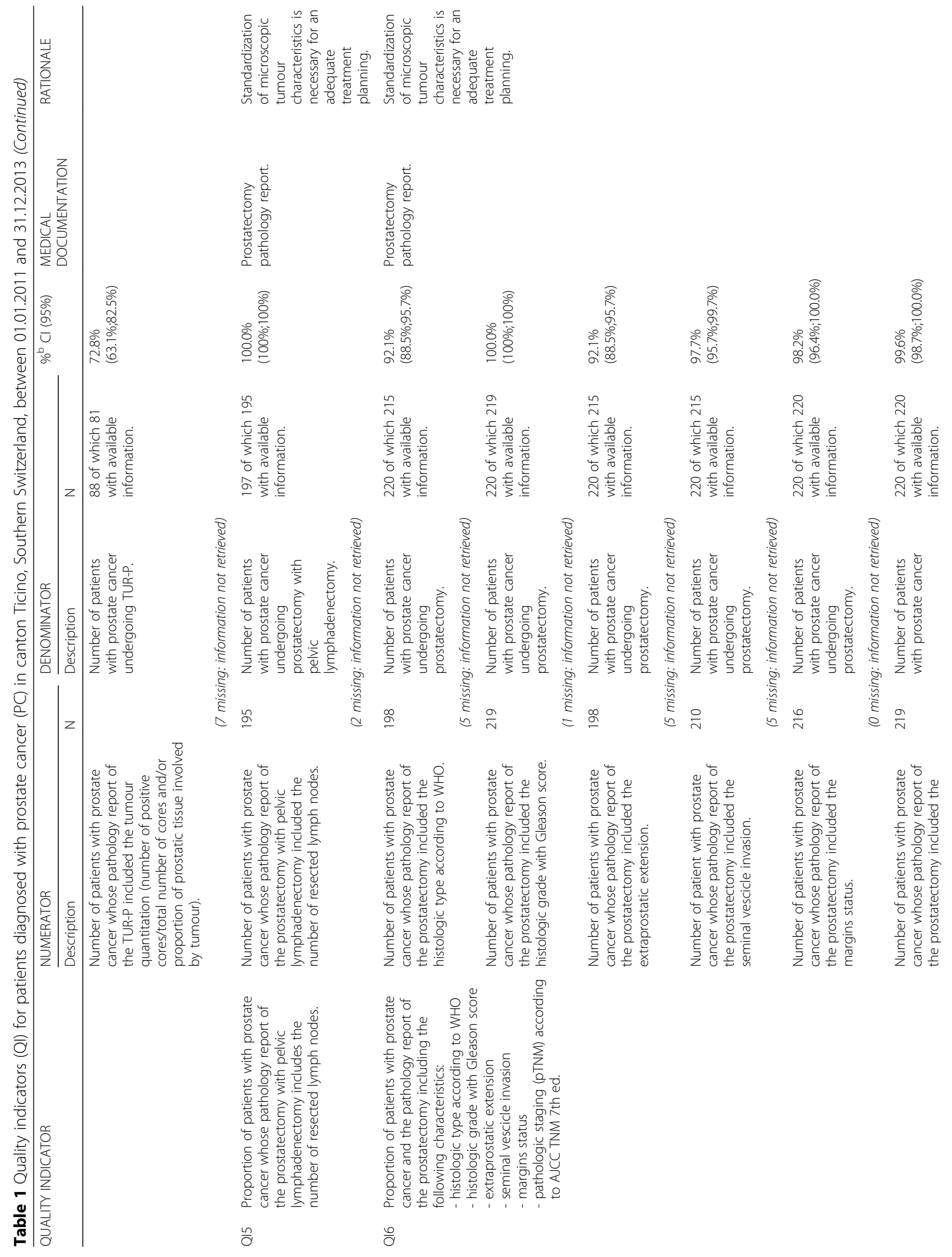




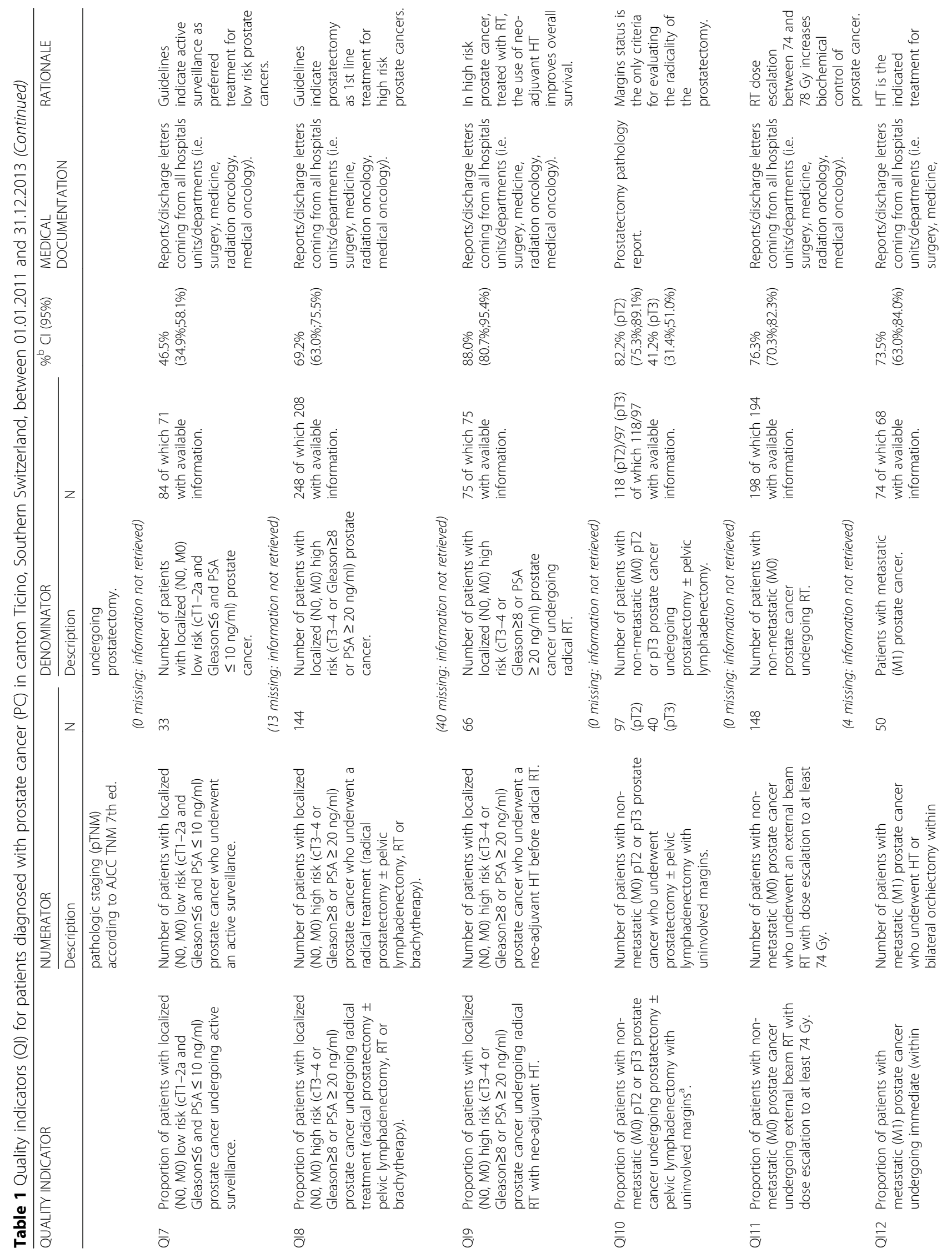




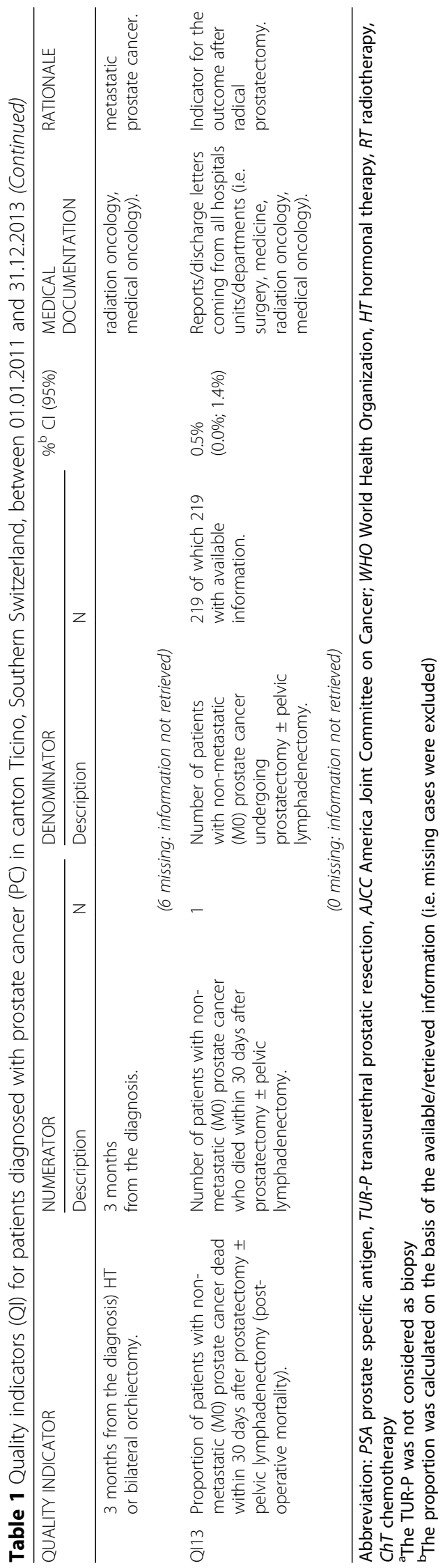




\section{Quality indicators for treatment}

QI7-12 refer to treatment modalities for PC and assess the compliance with the European guidelines [20, 21]. QI7-9 stratify localized prostate cancers (N0, M0) according to the D'Amico classification of risk and recurrence. Thirty-three patients (46.5\%; CI95\%: 34.9\%; 58.1\%) with a low risk PC underwent active surveillance (QI7) and 144 patients (69.2\%; CI95\%: 63.0\%; 75.5\%) with a high risk PC were treated radically through prostatectomy (with or without pelvic lymphadenectomy), radiotherapy or brachytherapy (QI8). Furthermore, 66 patients (88.0\%; CI95\%: 80.7\%; 95.4\%) with a high risk PC undergoing radiotherapy performed in addition a neo-adjuvant hormonal treatment (QI9). Among PC patients undergoing radical prostatectomy (with or without pelvic lymphadenectomy), 97 with stage pT2 (82.2\%; CI95\%: 75.3\%; 89.1\%) and 40 with pT3 (41.2\%; C195\%: 31.4\%; 51.0\%) had uninvolved margins (QI10). 148 (76.3\%; CI95\%: 70.3\%; 82.3\%) patients with localized non-metastatic PC (M0) treated with external beam radiotherapy underwent a dose escalation to at least 74 Gy (QI11). QI12 analysed the treatment for metastatic (every T, every N, M1) PC: 50 patients (73.5\%; C195\%: 63.0\%; $84.0 \%$ ) underwent hormonal therapy within 3 months from the date of the diagnosis.

\section{Quality indicator for outcome}

QI13 evaluated the outcome for non-metastatic (M0) PC after the radical prostatectomy (with or without pelvic lymphadenectomy), accounting only 1 death within 30 days from the surgical intervention $(0.5 \%$; CI95\%: $0.0 \% ; 1.4 \%)$.

\section{Discussion}

The present population-based study allowed to evaluate the QoCC for PC and to find out possible weaknesses in the care system of canton Ticino, southern Switzerland. PC diagnosis and treatment reflect the recommendations of the guidelines and state a good quality level of the cancer care in our region compared with other countries. Particularly, the $69 \%$ of high-risk PC patients underwent radical treatment (72\% in the U.S. and $66 \%$ in Australia) whereas $88 \%$ of them benefited of neo-adjuvant HT in addition to RT (92\% in Sweden) [22-24]. On the other hand, there is still room for improvement regarding HT for metastatic patients $(73 \%$ in southern Switzerland versus $88 \%$ in Sweden) and for prostatectomy specimens' margins, which were uninvolved in $82 \%$ pT2 cases in our region (92\% in Germany) [24, 25].

A first strength of this study is the selection procedure of the QI, described in Bianchi et al. [17]: the validated Delphi methodology together with local and international experts' advices assured an adequate evaluation of relevance, validity and feasibility of QI. In addition, a possible selection bias is avoided and a representation of the entire regional health care system is guaranteed, thanks to the population-based data collection and the Cancer Registry access to public and private data sources. According to Lorez et al. the registration completeness for PC in canton Ticino is $87.3 \%$ (mean value for all Swiss cancer registries is $87.9 \%$ ), confirming a satisfactory coverage level [26]. The direct extraction of information from the original medical documentation assures a homogeneous codification as well as a high grade of coherence.

A limit of the present study could be the lack of information for a few QI. Particularly for QI7 and QI8 we observed a large percentage of "missing" cases. In general, we had some difficulties in getting the complete medical documentation needed to assess the performed therapeutic treatment prospectively. One reason could be that some patients underwent PC treatments outside of canton Ticino (i.e. in other cantons), hence there was a consistent time gap before getting the needed information. Consequently, for these QI we had larger 95\% CI, possibly affecting the statistical power of the analysis. This could be solved extending the observation period or the population at risk for future projects and could be a strong motivation to stimulate and improve the communication among public and private facilities and cancer registries. Furthermore, we faced some difficulties in finding comparison data in the literature, particularly at the population-based level, because of different selection criteria, surgical procedures and pathological protocols, heterogeneous adhesion to specific national/international guidelines as well as general lack in QI definition and standardization; these aspects could limit the potential value of such studies. Another limitation of the study could be the literature research performed to select comparative studies that could have missed some relevant studies.

In the following paragraph we describe the results of each QI in comparison with similar data in the available literature.

QI1. In order to have an accurate staging of the disease and a better treatment planning, the diagnosis should be confirmed histologically [27-33]. In fact, the results of imaging studies, such as computerised tomography scans or magnetic resonance imaging, are not enough to determine the tumour type. In our analysis the transurethral prostatic resection (TUR-P) is not considered as needle-biopsy. Our result is in line with other population-based studies: 84.7 and $78.8 \%$ of PC were diagnosed through a transrectal ultrasound guided biopsy, in the regions of South Australia and Victoria and in Denmark respectively [23, 34].

QI2. The ideal number of cores to be taken varies in relation with the volume of the prostatic gland and is still object of many systematic reviews and randomized and non-randomized clinical trials [30, 35-38]. 
International guidelines recommend taking a minimum of 8 cores but not more than 12 , because there is no significant improvement in cancer detection rate [3941]. In our study $72.5 \%$ of patients had 8 or more biopsy cores. Particularly, 65.3\% of patients had 8 to 12 biopsy cores, a comparable result to that reported in Spain (64.6\%), but lower than in Denmark (78.8\%) [34, 42]. Compared to Sweden, where $73 \%$ of patients had between 10 and 12 cores taken and 11\% between 6 and 9, in southern Switzerland there was a lower proportion of patients with 10-12 biopsy cores (25\%) and with 69 cores taken (63\%) [24]. We believe that a major factor influencing this difference could be the application of different national/international guidelines.

QI3-4. The information reported in the pathology report of needle biopsies and transurethral prostatic resection (TUR-P) are essential for an optimal treatment planning (choice of therapy, risk evaluation linked with the clinical status of the patient, probability to develop distant metastasis) and for the prognosis of PC [43]. According to the guidelines published by the College of American Pathologists, the European Society of Uropathology and the Swiss Society of Pathology, the information about tumour histology, Gleason score and quantification of tissue involved by the tumour have to be specified in the pathology report of needle biopsies and TUR-P [18, 19, 44]. Despite the presence in the literature of many studies assessing the importance of such factors in the therapeutic choices, we could only find a Danish study and two American studies illustrating the proportion of biopsy reports including Gleason score for AJCC stage I-II PC. The reported percentages (97.3, 89.3 and 92.0\%) were lower than that of southern Switzerland (100.0\%), confirming the elevated quality of work performed from the local institute of pathology [45-47].

QI5-6. As stated for QI3 and QI4, also the standardization of the pathological evaluation of the prostatectomy specimen plays a central role in the PC patients' care, the adequate treatment decision planning, such as an eventual adjuvant therapy and the prognosis estimation. In the literature we found only two American studies assessing the quality of surgical pathology reporting $[48,49]$. As shown in Fig. 1 the results obtained in canton Ticino appeared to be comparable to the U.S.

QI7. There are various options for PC treatment depending on different factors such as stage of the disease, PSA value, Gleason score, as well as patient's comorbidities and life expectancy. The introduction of PSA screening for the early diagnosis increased the detection of PC that otherwise would have remained silent. To limit the risk of overtreatment, the European guidelines recommend active surveillance as primary treatment for low risk PC [50]. As shown in Fig. 2 there are several studies identifying the proportion of patients with low risk PC undergoing active surveillance, which varies from $16.2 \%$ in Germany to

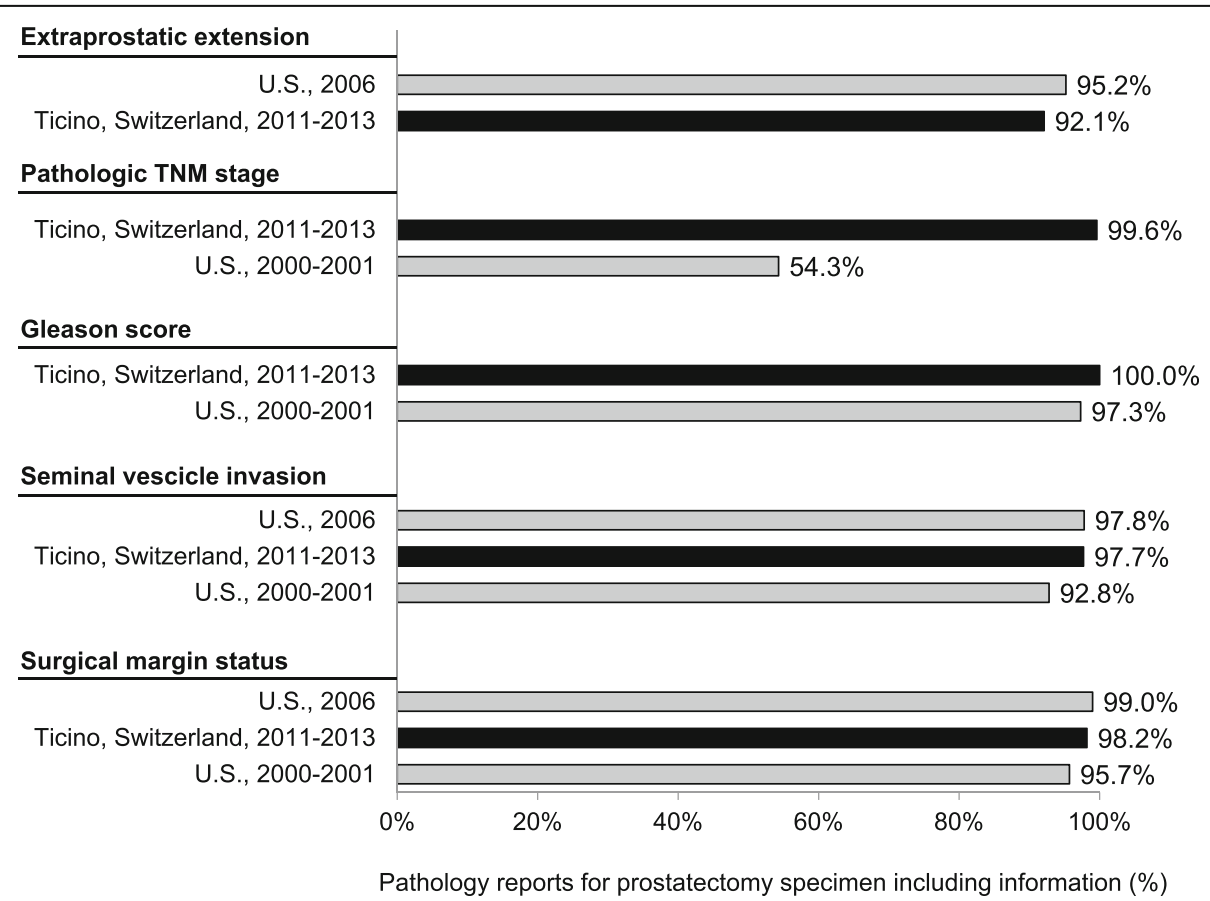

Fig. 1 Ql6. Completeness of pathology reports for prostatectomy specimens: comparison between southern-Switzerland and U.S 


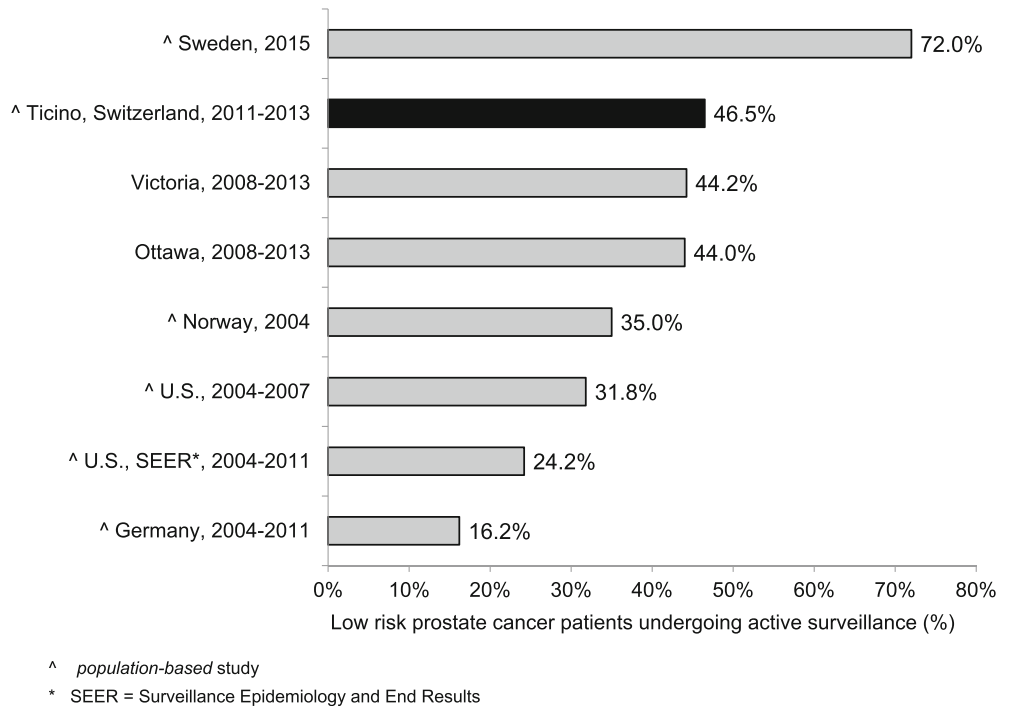

Fig. 2 Q17. Proportion of patients with low-risk prostate-cancer undergoing active-surveillance: comparison between southern-Switzerland and other countries

$72.0 \%$ in Sweden, the only country with a higher proportion than that reported in southern Switzerland [24, 51-55]. Moreover, during more recent years we detected an increase in the use of active surveillance as management option to decrease overtreatment, confirming the agreement to recent guidelines $[56,57]$. QI8. Actually, there is no general consensus on the optimal treatment modalities for high risk PC, showing an increased risk of PSA failure and metastatic progression. Specialist's recommendations and patient's preferences, especially in relation to side effects of the therapy and their impact on the quality of life, play a relevant role during the choice of the treatment modality. Radical prostatectomy plus pelvic lymphadenectomy as well as radiation therapy plus hormone treatment are the recognized options for high risk PC [57]. Despite the consistent number of missing cases $(16.1 \%)$, related to the difficulty in retrieving information from the involved clinicians, results from southern Switzerland were comparable with other countries as shown in Fig. 3 [22-24, 53]. There is room for improvement in the harmonization and the

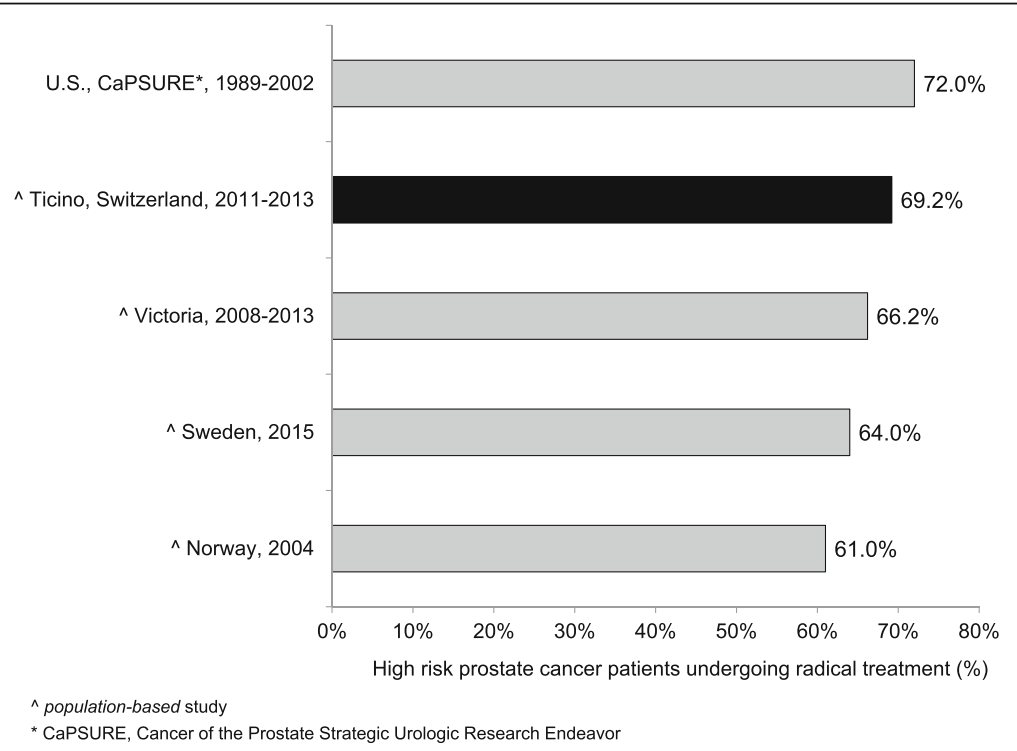

Fig. 3 QI 8. Proportion of patients with high-risk prostate-cancer undergoing radical treatment: comparisons between southern-Switzerland and other countries 
collaboration among clinicians, hospitals and cancer registries.

QI9. Guidelines recommend neoadjuvant and concurrent androgen deprivation therapy for patients with high risk PC receiving radical radiotherapy [57]. The value of neoadjuvant therapy is plenty described in randomized trials, such as the TROG trial that showed an improvement in 10-year PC-specific mortality in the group of patients receiving radiotherapy and neoadjuvant hormonal therapy [58]. Despite the presence of many trials evaluating the efficacy and the best duration of neoadjuvant hormonal treatment, there are only few studies, in particular at the population-based level, describing the percentage of high-risk patients undergoing neoadjuvant treatment before radical radiotherapy. Indeed we found out only a populationbased Swedish study, which reported a proportion of patients undergoing neoadjuvant treatment equal to $92 \%$, close to $88 \%$ observed in southern Switzerland [24]. QI10. The criteria scientifically recognized to evaluate the efficacy of the radical prostatectomy is the margins status of the resected specimen. The percentage of patients with negative margins (R0, i.e. the tumour doesn't reach the margins) depends on the surgeon's experience, tumour extension, methods of histologic evaluation and patients' characteristics such as comorbidities and overweight. By contrast, positive margins (R1) suggest an incomplete resection of the tumour and, therefore, represent an indicator for the execution of adjuvant treatment. Moreover, margins status is an important independent prognostic factor for PC biochemical recurrence and disease-free survival [59-61]. We calculated QI10 separately for PC confined to the prostate (pT2) and PC extended through the prostate capsule (pT3). A recent study conducted at the Ontario Cancer Care recommends to reach a minimum of $75 \%$ of patients with negative margins for $\mathrm{pT} 2$ disease [62]. Our result is therefore higher than this recommendation, but there is still room for improvement, as shown in Fig. 4 [24, 25, 63-69]. A systematic review of studies published between 2008 and 2011, reported an overall rate of $\mathrm{PC}$ with negative surgical margins equal to 91\% for pT2 stage (range: 77-96\%) and 63\% for pT3 stage (range: 50-71\%) [70]. In southern Switzerland, the proportion of pT3 PC with R0 was $41.2 \%$, result much lower than that reported in Canada (47.3\%), France (65.0\%) and Denmark (70.0\%, population-based study) $[63,65,68]$.

QI11. Radiotherapy is an alternative treatment to radical prostatectomy for localized (M0) PC, warranting the same survival probability and a comparable quality of life compared to surgery. Technical improvements, such as three-dimensional conformal radiotherapy and intensity modulated external-beam techniques, allowed to boost the dose of radiations directly on the tumour volume, reducing the irradiation of the surrounding tissue and the collateral effects. Several randomised and nonrandomised trials showed a significant impact of the dose

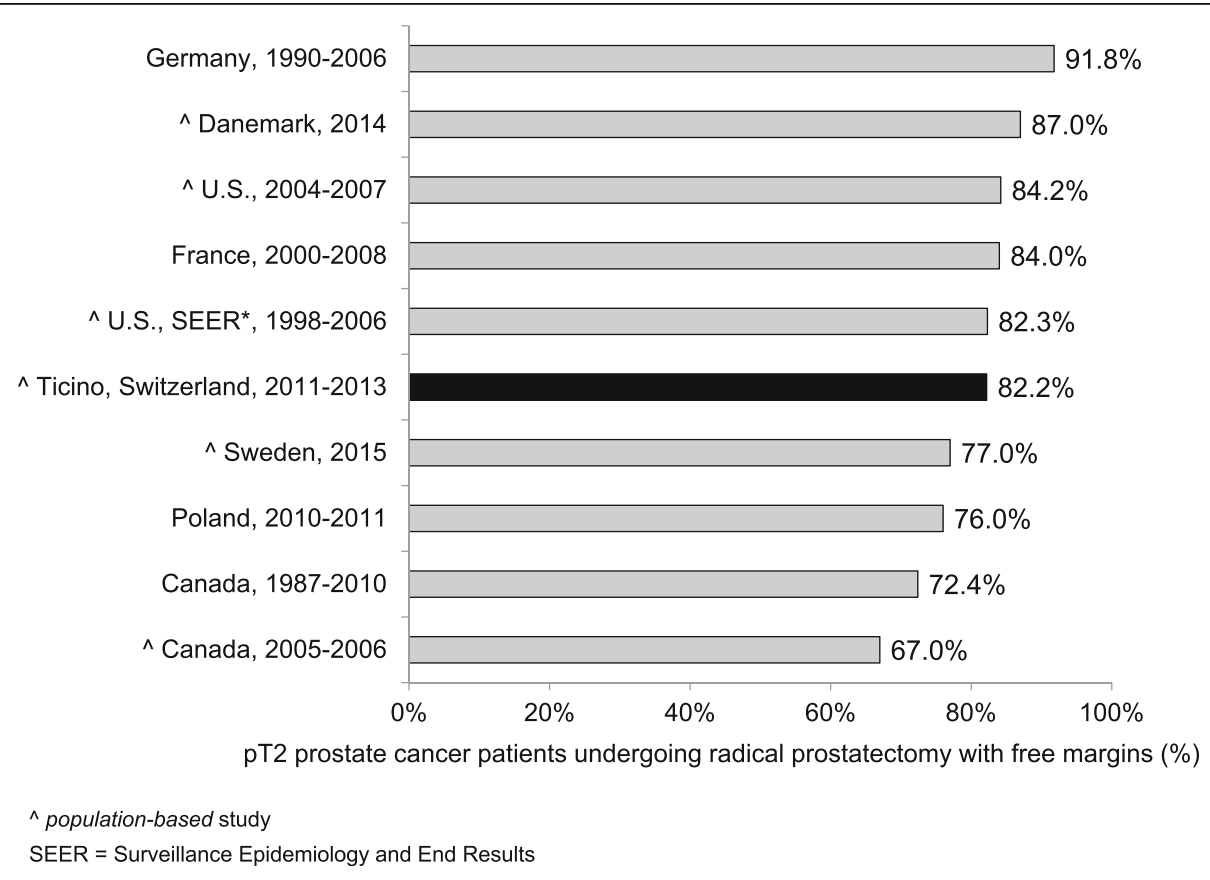

Fig. 4 Q110. Proportion of patients with pT2 prostate-cancer with free-margins after radical-prostatectomy: comparison between southern-Switzerland and other countries 


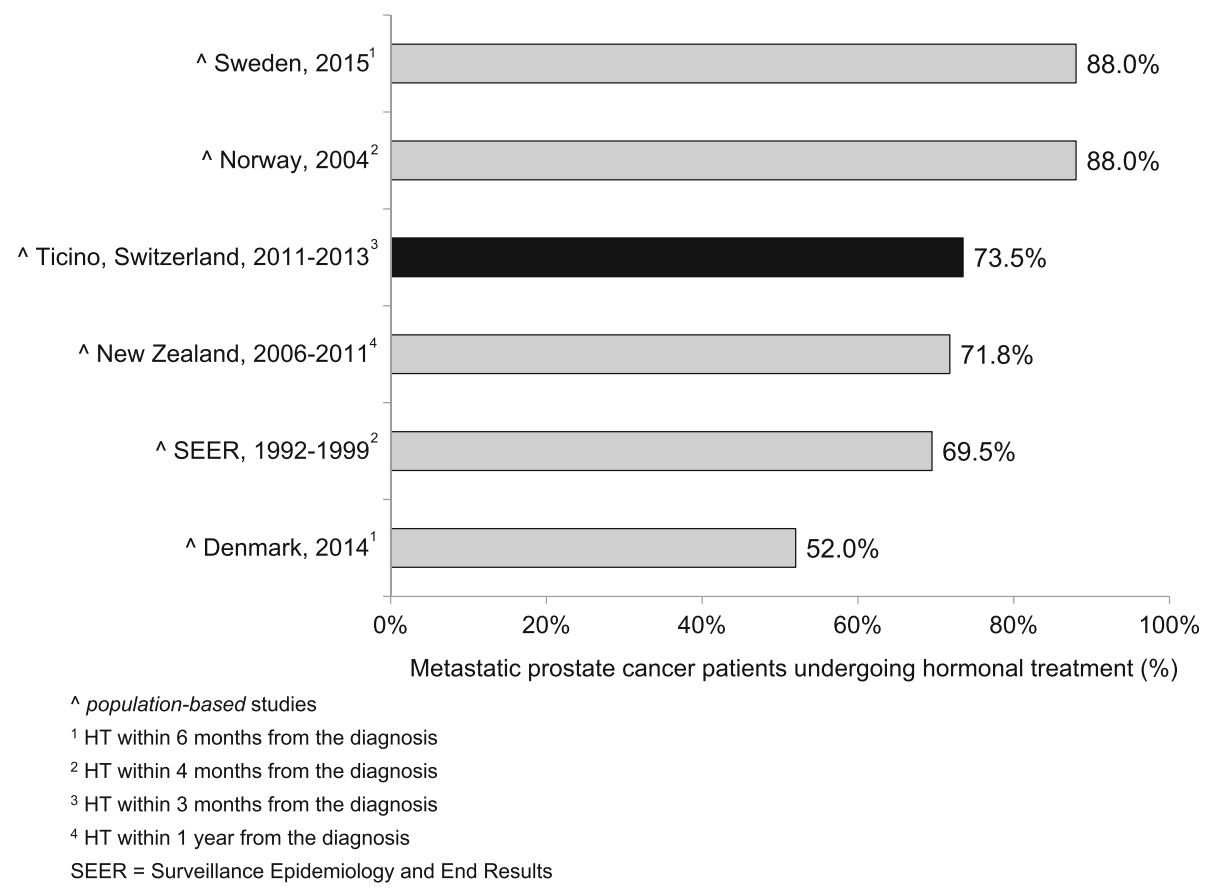

Fig. 5 Q112. Proportion of patients with metastatic prostate-cancer (M1) treated with hormonal-therapy: comparison between southern-Switzerland and other countries

escalation on biochemical recurrence: doses between 74 and $78 \mathrm{~Gy}$, in comparison with 64-70 Gy, increase significantly the progression free survival and extend the time frame before salvage hormonal therapy [71-74]. The European Association of Urology recommends therefore to use a minimum dose greater than $74 \mathrm{~Gy}$, recommendation used to define the QI11 [56]. Despite the plenty of trials analysing the efficacy and related collateral effects of radiotherapy, we could find only two population-based studies to compare our result: both of them reported a lower proportion $(66.8 \%$ in Sweden and $22.0 \%$ in the U.S.) of patients treated with at least 74 Gy than that observed in southern Switzerland (76.3\%) $[24,75]$

QI12. For metastatic PC the main goals of treatment are to increase survival and prevent/retard the

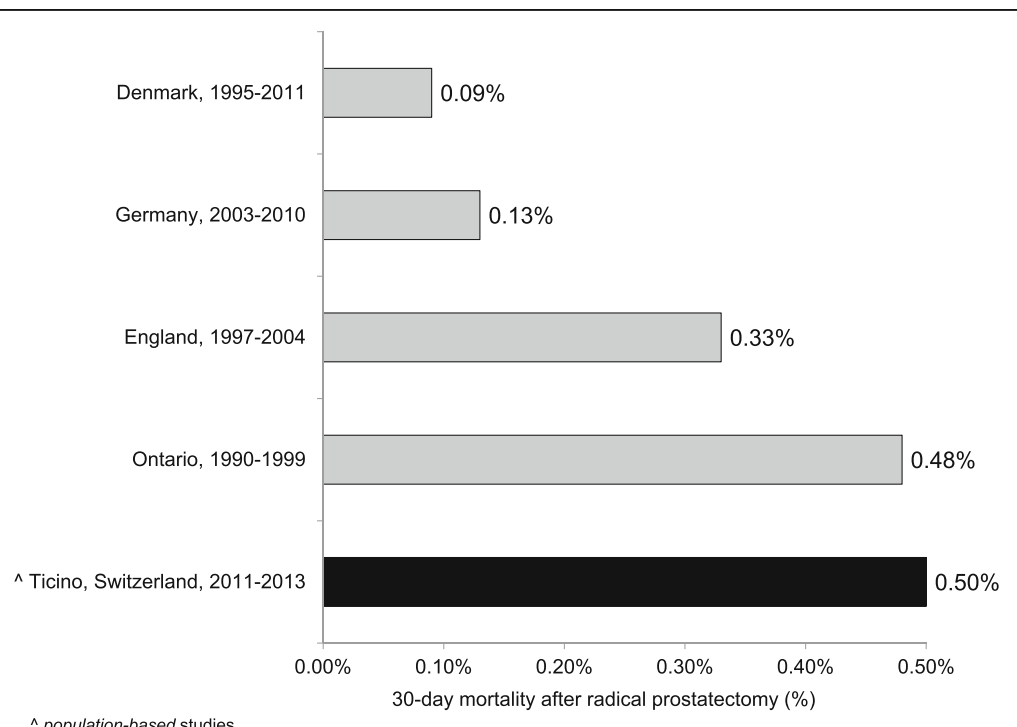

Fig. 6 Q113. Proportion of patients with prostate-cancer died within 30-days from radical-prostatectomy: comparison between southern-Switzerland and other countries 
appearance of symptoms due to disease's progression in order to improve the quality of life. Hormonal therapy is the used method to palliate symptoms and defer progression and disease progression-related complications [56]. The most rapid method to reduce the circulating testosterone level is the bilateral orchiectomy. Pharmacologic castration, obtained through the use of LHRH analogue or antagonist, is reversible (at least partially) and is often psychologically better accepted than orchiectomy. The question whether the beginning of hormonal therapy for asymptomatic patients should be performed immediately after the time of diagnosis or delayed until the biochemical progression is still questioned [56]. In our study we considered the proportion of PC patients undergoing hormonal therapy within three months from the diagnosis, being $73.5 \%$. In the literature we could compare studies considering different time frames between the diagnosis and the beginning of hormonal therapy. The proportion of metastatic PC treated with hormonal therapy varies from $52.0 \%$ in Denmark to 88.0\% in Sweden and Norway (Fig. 5) [24, 53, 63, 76-78]. We, then, believe that here could be room for improvement in southern Switzerland, since almost a quarter of metastatic PC patients do not receive hormonal therapy within three months from the diagnosis, but even extending the time frame to 6 months or 1 year.

QI13. The postoperative mortality within 30 days after prostatectomy is affected by different factors linked whether with the patient (age, comorbidities, general health status) as with the healthcare system quality and safety $[79,80]$. Hospital procedural volume is inversely associated with in-hospital mortality, length of stay and intra- and postoperative complications [81, 82]. The low postoperative mortality observed in southern Switzerland $(0.5 \%)$ was comparable with the few literature data (see Fig. 6).

\section{Conclusions}

The results of the present study on the QoCC for PC in southern Switzerland give an encouraging and positive picture of the local health care system, although some improvements are still possible. Through this study we assessed the feasibility of data collection and evaluation of QI at the population-based level through cancer registry activity. Standardisation of QI definition as well as further population-based data are needed to set suitable target requirements in order to guarantee a good quality level of the standard of care. The short-term assessment of the diagnostic and therapeutic process through QoCC, could allow taking the necessary measures in the daily clinical practice to ensure an adequate standard of care translating into an immediate benefit for the patients.

\section{Additional file}

Additional file 1: List of QI assessed and selected for prostate cancer, according to the clinical domain. This file describes the full list of selected Ql for prostate cancer. (PDF $142 \mathrm{~kb}$ )

\section{Abbreviations}

PC: Prostate cancer; QI: Quality indicators; QoCC: Quality of cancer care; TURP: Transurethral prostatic resection

\section{Acknowledgements}

We are particularly grateful to the $\mathrm{QC}_{3} \mathrm{PC}$ Working Group, who contributed to critically review the $\mathrm{QC}_{3} \mathrm{PC} \mathrm{Ql}$, for their precious collaboration. We confirm that all the people mentioned here below provide their permission to be included in this section:

Giorgio, Ballerini, Radiation Oncology Dept., Clinica Luganese, 6900 Lugano, Switzerland.

Gianni, Casanova, Urology Dept., Clinica Luganese, 6900 Lugano, Switzerland. Mauro, Castelnuovo, Urology Dept., Ospedale Regionale di Lugano, 6900 Lugano, Switzerland.

Michele, Ghielmini, Medical Oncology Dept., Oncology Institute of Southern Switzerland (|OSI), 6500 Bellinzona, Switzerland.

Luca, Giovanella, Nuclear Medicine Dept., Oncology Institute of Southern

Switzerland (IOSI), 6500 Bellinzona, Switzerland.

Fernando, Jermini, Urology Dept., Ospedale Regionale di Lugano, 6900

Lugano, Switzerland.

Anna, Lladò, Medical Oncology Dept., Oncology Institute of Southern Switzerland (|OSI), 6500 Bellinzona, Switzerland.

Luca, Mazzucchelli, Clinical Pathology, Cantonal Institute of Pathology, 6600 Locarno, Switzerland.

Augusto, Pedrazzini, Medical Oncology Dept., Ospedale Regionale di

Locarno, 6600 Locarno.

Gianfranco, Pesce, Radiation Oncology Dept., Oncology Institute of Southern Switzerland (IOSI), 6500 Bellinzona, Switzerland.

Enrico, Roggero, Medical Oncology Dept., Oncology Institute of Southern Switzerland (|OSI), 6500 Bellinzona, Switzerland.

Flavio, Stoffel, Urology Dept., Ospedale Regionale di Bellinzona e Valli, 6500 Bellinzona, Switzerland.

Giordano, Venzi, Urology Dept., Ospedale Regionale di Lugano, 6900 Lugano, Switzerland.

Rolf, Wyttenbach, Radiology Dept., Ospedale Regionale di Bellinzona e Valli, 6500 Bellinzona, Switzerland.

\section{Funding}

This work was supported by Krebsforschung Schweiz, grant number KFS 02668-08-2010, and by Advisory Board Research Ente Ospedaliero Cantonale Bellinzona, grant number ABREOC 10/2010.

The funding sources have not any involvement in the study design, in the collection, analysis and interpretation of data, in the writing of the report and in the decision to submit the paper for publication.

\section{Availability of data and materials}

The data that support the findings of the current study are not publicly available due to individual privacy reasons, but are available from the corresponding author on reasonable request.

\section{Authors' contributions}

I declare that: $L O, A S, L M$, and $A B$ have directly participated in the conducting of the project and planning of the manuscript; $L O$ and $A B$ in the reporting and acquisition of data; LO in the analysis of data. Finally, I declare that all the Authors have drafted and revised the paper critically for important intellectual content and interpretation, and that they have given final approval of the version published.

Ethics approval and consent to participate

Data collection on cancer cases is authorized and regulated by the following cantonal law and the concerning regulation:

- Legge sul registro dei tumori del 21 giugno 1994: https://m3.ti.ch/ CAN/RLeggi/public/index.php/raccolta-leggi/legge/vid/18b; 
- Regolamento della Legge sul Registro dei tumori del 9 giugno 1998: https://m3.ti.ch/CAN/RLeggi/public/index.php/raccolta-leggi/legge/ vid/06_31.

According to the above mentioned law and regulation, the present study needs no formal ethics approval and the informed consent to participate is not necessary.

\section{Consent for publication}

Not applicable.

\section{Competing interests}

The authors declare that they have no competing interests.

\section{Publisher's Note}

Springer Nature remains neutral with regard to jurisdictional claims in published maps and institutional affiliations.

\section{Author details}

'Ticino Cancer Registry, Cantonal Institute of Pathology, Via in Selva 24, 6600 Locarno, Switzerland. ${ }^{2}$ Clinical Pathology, Cantonal Institute of Pathology, 6600 Locarno, Switzerland.

\section{Received: 15 March 2018 Accepted: 18 June 2018}

\section{Published online: 11 July 2018}

\section{References}

1. Ferlay J, Steliarova-Foucher E, Lortet-Tieulent J, Rosso S, Coebergh JW, Comber H, Forman D, Bray F. Cancer incidence and mortality patterns in Europe: estimates for 40 countries in 2012. Eur J Cancer. 2013;49:1374-403.

2. Arndt V, Feller A, Hauri D, Heusser R, Junker C, Kuehni C, Lorez M, Pfeiffer V, Schindler M. Schweizerischer Krebsbericht 2015. Stand und Entwicklungen. Neuchâtel: Office féderal de la statistique (OFS); 2016.

3. Campbell SM, Roland MO, Buetow SA. Defining quality of care. Soc Sci Med. 2000;51:1611-25.

4. Malin JL, Schneider EC, Epstein AM, Adams J, Emanuel EJ, Kahn KL. Results of the National Initiative for Cancer care quality: how can we improve the quality of cancer care in the United States? J Clin Oncol. 2006;24:626-34.

5. Schneider EC, Malin JL, Kahn KL, Emanuel EJ, Epstein AM. Developing a system to assess the quality of cancer care: ASCO's national initiative on cancer care quality. J Clin Oncol. 2004;22:2985-91.

6. Peppercorn JM, Weeks JC, Cook EF, Joffe S. Comparison of outcomes in cancer patients treated within and outside clinical trials: conceptual framework and structured review. Lancet. 2004;363:263-70.

7. National Institute for Cancer Epidemiology and Registration (NICER). http:// www.nicer.org/. 2016. Accessed July 2017.

8. Parkin DM, Chen WW, Ferlay J, Galceran J, Storm HH, Whelan SL. Comparability and quality control in cancer registration. IARC technical report no 19. Lyon: IARC; 2004.

9. Tyczynski JE, Démaret E, Parkin DM. Standards and guidelines for cancer registration in Europe. The ENCR recommendations. Volume 1. IARC Technical Publication n. 40. Lyon: IARC; 2003.

10. Eble JNSG, Epstein J, Sesterhenn I. Pathology and Genetics of Tumours of the Urinary System and Male Genital Organs. 3rd ed. Lyon: IARCPress; 2004.

11. Edge SB, Byrd DR, Carducci MA, Compton CC. AJCC Cancer staging manual. 7th ed. New York: Springer-Verlag; 2010

12. Ferlay J, Burkhard C, Whelan S, Parkin DM. Check and conversion programs for Cancer registries (IARC/IACR tools for Cancer registries). IARC technical report no. 42. Lyon: IARC; 2005

13. Martos C, Crocetti E, Visser O, Rous B. Cancer Data Quality Checks Working Group: A proposal on cancer data quality check: one common procedure for European cancer registries. Luxembourg: Publications Office of the European Union; 2014

14. European Commission Joint Research Centre: JRC-ENCR quality check software, version 1.7.1. Available from: https://www.encr.eu/tools-forregistries; 2016. Accessed July 2017.

15. Bordoni A, Spitale A, Ortelli L, Mazzola P, Peverelli S: Registro cantonale dei tumori http://www.ti.ch/cancer. 2017. Accessed July 2017.

16. Bullard J, Coleman MP, Robinson D, Lutz JM, Bell J, Peto J. Completeness of cancer registration: a new method for routine use. $\mathrm{Br} J$ Cancer. 2000;82:1111-6.
17. Bianchi V, Spitale A, Ortelli L and the QC3 CRC Working Group. Quality indicators of clinical cancer care (QC3) in colorectal cancer. BMJ Open. 2013; https://doi.org/10.1136/bmjopen-2013-002818.

18. Srigley JR, Humphrey PA, Amin MB, Chang SS, Egevad L, Epstein Jl, Grignon DJ, McKiernan JM, Montironi R, Renshaw AA, et al. Protocol for the examination of specimens from patients with carcinoma of the prostate gland. Arch Pathol Lab Med. 2009;133(10):1568-76.

19. Boccon-Gibod L, van der Kwast TH, Montironi R, Boccon-Gibod L, Bono A. European Society of U, European Society of Pathology Uropathology Working G: handling and pathology reporting of prostate biopsies. Eur Urol. 2004:46:177-81.

20. Horwick A, Parker C, Bangma CH, Kataya V. Prostate Cancer: ESMO clinical practice guidelines for diagnosis, treatment and follow-up. Ann Oncol. 2010; 21:v129-33.

21. Heidenreich A, Aus G, Bolla M, Joniau S, Matveev VB, Schmid HP, Zattoni F. European Association of U: EAU guidelines on prostate cancer. Eur Urol. 2008;53:68-80.

22. Kawakami J, Cowan JE, Elkin EP, Latini DM, DuChane J, Carroll PR, Ca PI. Androgen-deprivation therapy as primary treatment for localized prostate cancer: data from Cancer of the prostate strategic urologic research endeavor (CaPSURE). Cancer. 2006;106:1708-14.

23. Ruseckaite R, Beckmann K, O'Callaghan M, Roder D, Moretti K, Millar J, Evans S. A retrospective analysis of Victorian and south Australian clinical registries for prostate cancer: trends in clinical presentation and management of the disease. BMC Cancer. 2016:16:607.

24. Stättin P, Sandin F, Robinson D, Franck Lissbrant I, Hjälm Eriksson M. Prostate cancer. In: Report from the national prostate cancer register 2015. Uppsala Örebro: Regionalt cancercentrumm. 2016; http://npcr.se/rapporter/ nationella-arsrapporter/. Accessed on July 2017.

25. Pfitzenmaier J, Pahernik S, Tremmel T, Haferkamp A, Buse S, Hohenfellner M. Positive surgical margins after radical prostatectomy: do they have an impact on biochemical or clinical progression? BJU Int. 2008;102:1413-8.

26. Lorez M, Bordoni A, Bouchardy C, Buillard JP, Camey B, Dehler S, Frick H, Konzelmann I, Maspoli M, Mousavi SM, et al. Evaluation of completeness of case ascertainment in Swiss cancer registration. Eur J Cancer Prev. 2017;26:139-46.

27. Babaian RJ, Toi A, Kamoi K, Troncoso P, Sweet J, Evans R, Johnston D, Chen M. A comparative analysis of sextant and an extended 11-core multisite directed biopsy strategy. J Urol. 2000;163:152-7.

28. Hara R, Jo Y, Fujii T, Kondo N, Yokoyoma T, Miyaji Y, Nagai A. Optimal approach for prostate cancer detection as initial biopsy: prospective randomized study comparing transperineal versus transrectal systematic 12 core biopsy. Urology. 2008:71:191-5.

29. Takenaka A, Hara R, Ishimura T, Fujii T, Jo Y, Nagai A, Fujisawa M. A prospective randomized comparison of diagnostic efficacy between transperineal and transrectal 12-core prostate biopsy. Prostate Cancer Prostatic Dis. 2008;11:134-8.

30. Eichler K, Hempel S, Wilby J, Myers L, Bachmann LM, Kleijnen J. Diagnostic value of systematic biopsy methods in the investigation of prostate cancer: a systematic review. J Urol. 2006;175:1605-12.

31. Donovan J, Hamdy F, Neal D, Peters T, Oliver S, Brindle L, Jewell D, Powell P, Gillatt D, Dedman D, et al. Prostate testing for Cancer and treatment (ProtecT) feasibility study. Health Technol Assess. 2003;7:1-88.

32. Aron M, Rajeev TP, Gupta NP. Antibiotic prophylaxis for transrectal needle biopsy of the prostate: a randomized controlled study. BJU Int. 2000;85:682-5.

33. Presti JC Jr, O'Dowd GJ, Miller MC, Mattu R, Veltri RW. Extended peripheral zone biopsy schemes increase cancer detection rates and minimize variance in prostate specific antigen and age related cancer rates: results of a community multi-practice study. J Urol. 2003;169:125-9.

34. Helgstrand JT, Klemann N, Roder MA, Toft BG, Brasso K, Vainer B, Iversen P. Danish prostate Cancer registry - methodology and early results from a novel national database. Clin Epidemiol. 2016;8:351-60

35. Emiliozzi P, Scarpone P, DePaula F, Pizzo M, Federico G, Pansadoro A, Martini M, Pansadoro V. The incidence of prostate cancer in men with prostate specific antigen greater than $4.0 \mathrm{ng} / \mathrm{ml}$ : a randomized study of 6 versus 12 core transperineal prostate biopsy. J Urol. 2004;171:197-9.

36. Abd TT, Goodman M, Hall J, Ritenour CW, Petros JA, Marshall FF, Issa MM. Comparison of 12-core versus 8-core prostate biopsy: multivariate analysis of large series of US veterans. Urology. 2011;77:541-7.

37. Irani J, Blanchet P, Salomon L, Coloby P, Hubert J, Malavaud B, Mottet N. Is an extended 20-core prostate biopsy protocol more efficient than the standard 12-core? A randomized multicenter trial. J Urol. 2013;190:77-83. 
38. Cormio L, Scattoni V, Lorusso F, Perrone A, Di Fino G, Selvaggio O, Sanguedolce F, Bufo P, Montorsi F, Carrieri G. Prostate cancer detection rates in different biopsy schemes. Which cores for which patients? World J Urol. 2014;32:341-6.

39. Horwich A, Parker C, de Reijke T, Kataja V, Group EGW. Prostate cancer: ESMO clinical practice guidelines for diagnosis, treatment and follow-up. Ann Oncol. 2013;24(Suppl 6):vi106-14.

40. Heidenreich A, Bellmunt J, Bolla M, Joniau S, Mason M, Matveev V, Mottet N, Schmid HP, van der Kwast T, Wiegel T, et al. EAU guidelines on prostate cancer. Part 1: screening, diagnosis, and treatment of clinically localised disease. Eur Urol. 2011;59:61-71.

41. Mohler JL, Armstrong AJ, Higano C, Kantoff PW, Plimack ER. Prostate cancer. In: NCCN clincal practice guidelines in oncology (NCCN guidelines). Natl Compr Canc Netw. 2011; http://www.nccn.org. Accessed on January 2011.

42. Gomez-Veiga F, Rodriguez-Antolin A, Minana B, Hernandez C, Suarez JF, Fernandez-Gomez JM, Unda M, Burgos J, Alcaraz A, Rodriguez P, et al. Diagnosis and treatment for clinically localized prostate cancer. Adherence to the European Association of Urology clinical guidelines in a nationwide population-based study - GESCAP group. Actas Urol Esp. 2017;

43. Amin M, Boccon-Gibod L, Egevad LL. Prognostic and predictive factors and reporting of prostate carcinoma in prostate needle biopsy specimens. (2005 WHO-sponseored international consultation consensus). Scand J Urol Nephrol. 2004;2004:20-33.

44. Bubendorf L, Diener PA. Fleischmann A, Heilemariam S, Lehr A. Prostate. In: Recommandations pour la qualité SSPath. Societé Suisse de Pathologie. 2011. http://sgpath.ch/assurance-de-la-qualite/. Accessed on August 2013.

45. Roder MA, Brasso K, Christensen IJ, Johansen J, Langkilde NC, Hvarness H, Carlsson S, Jakobsen $\mathrm{H}$, Borre M, Iversen P. Survival after radical prostatectomy for clinically localised prostate cancer: a population-based study. BJU Int. 2014;113:541-7.

46. Ritchey J, Gay EG, Spencer BA, Miller DC, Wallner LP, Stewart AK, Dunn RL, Litwin MS, Wei JT. Assessment of the quality of medical care among patients with early stage prostate cancer undergoing expectant management in the United States. J Urol. 2012;188:769-74.

47. Spencer BA, Miller DC, Litwin MS, Ritchey JD, Stewart AK, Dunn RL, Gay EG, Sandler HM, Wei JT. Variations in quality of care for men with early-stage prostate cancer. J Clin Oncol. 2008;26:3735-42.

48. Idowu MO, Bekeris LG, Raab S, Ruby SG, Nakhleh RE. Adequacy of surgical pathology reporting of cancer: a College of American Pathologists Q-probes study of 86 institutions. Arch Pathol Lab Med. 2010;134:969-74.

49. Miller DC, Spencer BA, Shah RB, Ritchey J, Stewart AK, Gay EG, Dunn RL, Wei JT, Litwin MS. The quality of surgical pathology care for men undergoing radical prostatectomy in the U.S. Cancer. 2007;109:2445-53.

50. Heidenreich A, Bastian PJ, Bellmunt J, Bolla M, Joniau S, van der Kwast T, Mason M, Matveev V, Wiegel T, Zattoni F, et al. EAU guidelines on prostate cancer. Part 1: screening, diagnosis, and local treatment with curative intent-update 2013. Eur Urol. 2014;65:124-37.

51. Hager B, Kraywinkel K, Keck B, Katalinic A, Meyer M, Zeissig SR, Stabenow R, Froehner M, Huber J. Integrated prostate cancer centers might cause an overutilization of radiotherapy for low-risk prostate cancer: a comparison of treatment trends in the United States and Germany from 2004 to 2011. Radiother Oncol. 2015;115:90-5.

52. Weerakoon M, Papa N, Lawrentschuk N, Evans S, Millar J, Frydenberg M, Bolton D, Murphy DG. The current use of active surveillance in an Australian cohort of men: a pattern of care analysis from the Victorian prostate Cancer registry. BJU Int. 2015;115(Suppl 5):50-6.

53. Hernes E, Kyrdalen A, Kvale R, Hem E, Klepp O, Axcrona K, Fossa SD. Initial management of prostate cancer: first year experience with the Norwegian National Prostate Cancer Registry. BJU Int. 2010;105:805-11. discussion 811

54. Aizer AA, Paly JJ, Efstathiou JA. Multidisciplinary care and management selection in prostate cancer. Semin Radiat Oncol. 2013;23:157-64.

55. Cristea O, Lavallee LT, Montroy J, Stokl A, Cnossen S, Mallick R, Fergusson D, Momoli F, Cagiannos I, Morash C, Breau RH. Active surveillance in Canadian men with low-grade prostate cancer. CMAJ. 2016;188:E141-7.

56. Mottet N, Bellmunt J, Briers E, Van der Bergh RCN, Bolla M, Van Casteren NJ, Cornford P, Culine S, Joniau S, Lam T, et al: Guidelines on Prostate Cancer. Available from https://uroweb.org/wp-content/uploads/09-Prostate-Cancer_ LR.pdf (accessed on Juny 2017). European Association of Urology 2015. Accessed July 2017.

57. Parker C, Gillessen S, Heidenreich A, Horwich A, Committee EG. Cancer of the prostate: ESMO clinical practice guidelines for diagnosis, treatment and follow-up. Ann Oncol. 2015;26(Suppl 5):v69-77.
58. Roach M 3rd, Bae K, Speight J, Wolkov HB, Rubin P, Lee RJ, Lawton C, Valicenti R, Grignon D, Pilepich MV. Short-term neoadjuvant androgen deprivation therapy and external-beam radiotherapy for locally advanced prostate cancer: long-term results of RTOG 8610. J Clin Oncol. 2008;26:585-91.

59. Swindle P, Eastham JA, Ohori M, Kattan MW, Wheeler T, Maru N, Slawin K, Scardino PT. Do margins matter? The prognostic significance of positive surgical margins in radical prostatectomy specimens. J Urol. 2008;179:S47-51.

60. Yossepowitch O, Briganti A, Eastham JA, Epstein J, Graefen M, Montironi R, Touijer K. Positive surgical margins after radical prostatectomy: a systematic review and contemporary update. Eur Urol. 2014;65:303-13.

61. Karakiewicz PI, Eastham JA, Graefen M, Cagiannos I, Stricker PD, Klein E, Cangiano T, Schroder FH, Scardino PT, Kattan MW. Prognostic impact of positive surgical margins in surgically treated prostate cancer: multiinstitutional assessment of 5831 patients. Urology. 2005;66:1245-50.

62. Chin JL, Srigley J, Mayhew LA, Rumble RB, Crossley C, Hunter A, Fleshner N, Bora B, McLeod R, McNair S, et al. Guideline for optimization of surgical and pathological quality performance for radical prostatectomy in prostate cancer management: evidentiary base. Can Urol Assoc J. 2010;4:13-25.

63. Danish Prostate Cancer (DAPROCA) data Annual Report 2014 (online). Available from https://www.sundhed.dk/content/cms/86/15686_daproca_ \%C3\%A5rsrapport-2014_kommenteret_20150521final.pdf. Accessed July 2017.

64. Izard JP, Salazar MA, Chatterjee S, Lin DW, Wright JL. Positive surgical margins at radical prostatectomy: population-based averages within PSA and Gleason strata. Can Urol Assoc J. 2013;7:E561-6.

65. Ploussard G, Agamy MA, Alenda O, Allory Y, Mouracade P, Vordos D, Hoznek A, Abbou CC, de la Taille A, Salomon L. Impact of positive surgical margins on prostate-specific antigen failure after radical prostatectomy in adjuvant treatment-naive patients. BJU Int. 2011;107:1748-54.

66. Wright $J$, Dalkin BL, True LD, Ellis WJ, Stanford JL, Lange PH, Lin DW. Positive surgical margins at radical prostatectomy predict prostate cancer specific mortality. J Urol. 2010;183:2213-8.

67. Kamecki K, Biedka M, Makarewicz R, Siekiera J. Indications for postoperative radiotherapy in patients with prostate cancer after surgery with positive surgical margins. Contemp Oncol (Pozn). 2013;17:383-8.

68. Mauermann J, Fradet V, Lacombe L, Dujardin T, Tiguert R, Tetu B, Fradet $Y$. The impact of solitary and multiple positive surgical margins on hard clinical end points in 1712 adjuvant treatment-naive pT2-4 N0 radical prostatectomy patients. Eur Urol. 2013;64:19-25.

69. Lawrentschuk N, Evans A, Srigley J, Chin JL, Bora B, Hunter A, McLeod R, Fleshner NE. Surgical margin status among men with organ-confined (pT2) prostate cancer: a population-based study. Can Urol Assoc J. 2011;5:161-6.

70. Novara G, Ficarra V, Mocellin S, Ahlering TE, Carroll PR, Graefen M, Guazzoni G, Menon M, Patel VR, Shariat SF, et al. Systematic review and meta-analysis of studies reporting oncologic outcome after robot-assisted radical prostatectomy. Eur Urol. 2012;62:382-404.

71. Dearnaley DP, Hall E, Lawrence D, Huddart RA, Eeles R, Nutting CM, Gadd J, Warrington A, Bidmead M, Horwich A. Phase III pilot study of dose escalation using conformal radiotherapy in prostate cancer: PSA control and side effects. Br J Cancer. 2005;92:488-98.

72. Zietman AL, Bae K, Slater JD, Shipley WU, Efstathiou JA, Coen JJ, Bush DA, Lunt M, Spiegel DY, Skowronski R, et al. Randomized trial comparing conventional-dose with high-dose conformal radiation therapy in earlystage adenocarcinoma of the prostate: long-term results from proton radiation oncology group/american college of radiology 95-09. J Clin Oncol. 2010;28:1106-11.

73. Eade TN, Hanlon AL, Horwitz EM, Buyyounouski MK, Hanks GE, Pollack A. What dose of external-beam radiation is high enough for prostate cancer? Int J Radiat Oncol Biol Phys. 2007;68:682-9.

74. Kuban DA, Tucker SL, Dong L, Starkschall G, Huang EH, Cheung MR, Lee AK, Pollack A. Long-term results of the M. D. Anderson randomized doseescalation trial for prostate cancer. Int J Radiat Oncol Biol Phys. 2008;70:67-74.

75. Wang D, Ho A, Hamilton AS, Wu XC, Lo M, Fleming S, Goodman M, Thompson T, Owen J. Type and dose of radiotherapy used for initial treatment of non-metastatic prostate cancer. Radiat Oncol. 2014;9:47.

76. Fujimoto H, Nakanishi H, Miki T, Kubota Y, Takahashi S, Suzuki K, Kanayama HO, Mikami K, Homma Y. Oncological outcomes of the prostate cancer patients registered in 2004: report from the Cancer registration committee of the JUA. Int J Urol. 2011;18:876-81.

77. Lawrenson R, Obertova Z, Brown C, Fong P, Tyrie L, Scott N, Holmes M. The use of androgen deprivation therapy (ADT) and chemotherapeutic agents in New Zealand men with prostate Cancer. J Cancer. 2014;5:214-20. 
78. Keating NL, O'Malley AJ, McNaughton-Collins M, Oh WK, Smith MR. Use of androgen deprivation therapy for metastatic prostate cancer in older men BJU Int. 2008;101:1077-83.

79. Loppenberg B, Noldus J, Palisaar J. Complications of radical retropubic prostatectomies based on the Martin criteria. Urologe A. 2011;50:1403-11.

80. Alibhai SM, Leach M, Tomlinson G, Krahn MD, Fleshner N, Holowaty E, Naglie G. 30-day mortality and major complications after radical prostatectomy: influence of age and comorbidity. J Natl Cancer Inst. 2005; 97:1525-32.

81. Alibhai SM, Leach M, Tomlinson G. Impact of hospital and surgeon volume on mortality and complications after prostatectomy. J Urol. 2008;180:15562. discussion 162-153

82. Ellison LM, Heaney JA, Birkmeyer JD. The effect of hospital volume on mortality and resource use after radical prostatectomy. J Urol. 2000;163:867-9.

Ready to submit your research? Choose BMC and benefit from:

- fast, convenient online submission

- thorough peer review by experienced researchers in your field

- rapid publication on acceptance

- support for research data, including large and complex data types

- gold Open Access which fosters wider collaboration and increased citations

- maximum visibility for your research: over $100 \mathrm{M}$ website views per year 